\title{
DLTFS INVESTIGATION OF InGaAsN/GaAs TANDEM SOLAR CELL
}

\author{
Arpád Kósa * L Lubica Stuchlíková * Wojciech Dawidowski ${ }^{* *}$ \\ Juraj Jakuš ${ }^{*}$ - Beata Sciana ${ }^{* *}$ - Damian Radziewicz ${ }^{* *}$ \\ Damian Pucicki ${ }^{* *}$ _ Ladislav Harmatha * \\ Jaroslav Kováč ${ }^{*}$ - Marek Tłaczala ${ }^{* *}$
}

\begin{abstract}
In this paper authors present the results of identification of emission and capture processes in tandem solar cell structures based on quaternary InGaAsN semiconductor alloys by DLTFS (Deep Level Transient Fourier Spectroscopy) and by analytical evaluation processes. The energies of five trap levels ET1 $=0.77 \mathrm{eV}, \mathrm{ET} 2=0.47 \mathrm{eV}$, ET3 $=0.64 \mathrm{eV}, \mathrm{HT} 1=0.62 \mathrm{eV}$ and $\mathrm{HT} 2=0.53 \mathrm{eV}$ were identified with reliable accuracy. These values were obtained by available analytical procedures, verified by simulations and confirmed by reference structures with basic layer types and compared with possible reference trap data. Native structural defects in GaAs were stated as the origin of these deep energy levels.
\end{abstract}

K e y w or d s: tandem solar cell, deep level transient Fourier spectroscopy, deep energy levels

\section{INTRODUCTION}

The development and production of high quality materials is a crucial moment in the technical advancement of solar cells. However, obtaining a perfect crystal structure is nearly impossible due to the fact that it is very hard to ensure precise conditions of fabrication. In various cases it is unattainable to define the exact values of such factors as temperature, pressure and high purity. During the fabrication of these materials different types of impurities and defects are formed which can strongly affect the function and electrical properties of the final structures.

InGaAs and InGaAsN have attracted considerable attention due to their unique physical properties not only in the field of optoelectronic multi-junction solar cells, but also in heterojunction bipolar transistors and $1.2-1.3 \mu \mathrm{m}$ injection lasers [1]. This is allowed by a strong downward bowing of the band gap, by the incorporation of nitrogen. Unfortunately, InGaAsN exhibits a poor electronic quality caused mainly by the degradation of the material due to structural defects by incorporation of indium and nitrogen $[2,3]$.

The increasing requirements on the quality and efficiency of solar cells not only in space technology but also in terrestrial utilization has to be supported by various experiments and defect investigations on new materials and multilayer structures. The manufacture of high quality semiconductor materials must be supported by appropriate diagnostic methods. One of the most suitable diagnostic methods is Deep Level Transient Fourier Spectroscopy (DLTFS). DLTFS plays a key role in the investigation of the origin of defect states in semiconductor ma- terials and satisfies the basic requirements of diagnostics, especially accuracy, non-destructivity and sensitivity.

The aim of this work is to investigate the emission and capture processes on InGaAsN/GaAs semiconductor structures for tandem solar cell applications by the DLTFS method. Main attention was devoted to analytical procedures, evaluation methods, and comparison of the obtained results with reference structures and literature.

\section{EXPERIMENT}

The experimental part of this work included DLTFS measurements and initial evaluation processes, which were carried out on a tandem solar cell structure labelled as NI78n, and on three basic structures, thus two p-i-n samples labelled as X343n and X329n and an intrinsic GaAs active region labelled as X346n. In order to be able to determine the presence of complex defect states and trap parameters, various comparisons of measured results were conducted.

\subsection{Investigated samples}

The submitted structures were grown by AtmosphericPressure Metal-Organic Vapor-Phase Epitaxy (APMOVPE) technology on a GaAs substrate at Wroclaw University of Technology in Poland. Experiments of deep energy level investigation were performed at the Slovak University of Technology in Bratislava by the DLTFS measurement unit BioRad DL 8000. Initial and particular results are discussed. The InGaAsN/GaAs tandem solar cell structure NI78n was investigated under various DLTFS measurement conditions and input parameters.

\footnotetext{
* Institute of Electronics and Photonics, Faculty of Electrical Engineering and Information Technology, Slovak University of Technology, Ilkovičova 3, 81219 Bratislava, Slovakia, ${ }^{* *}$ Wrocław University of Technology, Faculty of Microsystem Electronics and Photonics, Janiszewskiego 11/17, 50-372 Wrocław, Poland. arpad.kosa@stuba.sk, lubica.stuchlikova@stuba.sk
} 


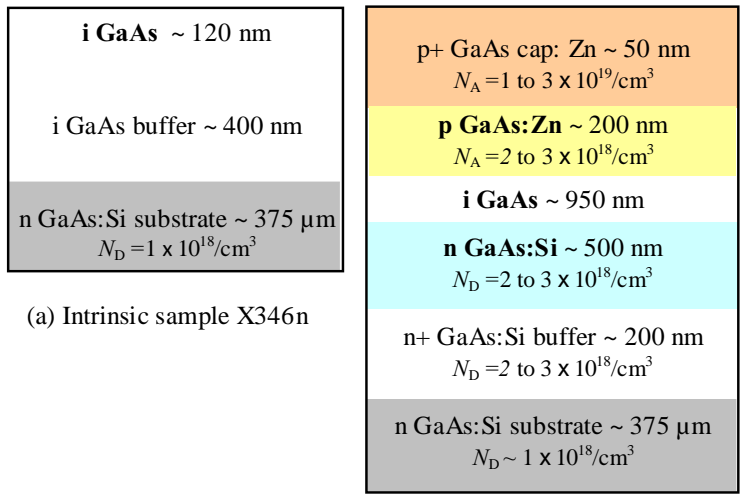

(b) Basic p-i-n structure X329n

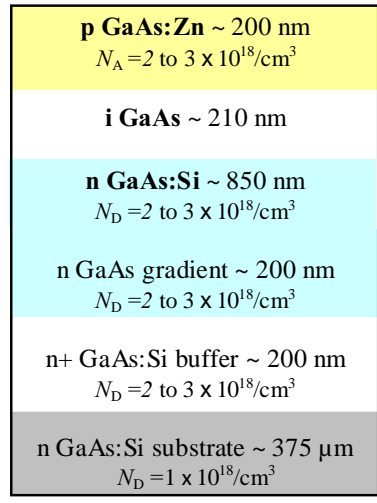

(c) Basic p-i-n structure X343n

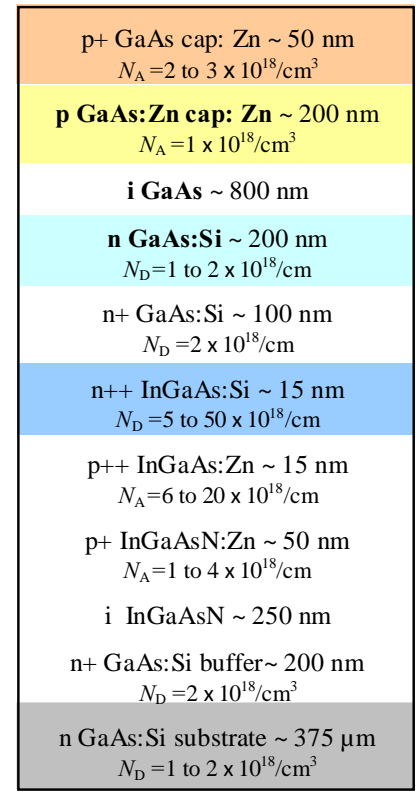

Fig. 1. Schematic view of the material compositions and layer structure properties of the investigated semiconductor samples, including a basic intrinsic GaAs structure (X346n), two p-i-n GaAs samples (X329n and X343n) and a tandem solar cell structure (NI78n)

Table 1. DLTFS measurement parameters

$\begin{array}{cccc}T_{W} & t_{P} & U_{R}(\mathrm{~V}) & U_{P}(\mathrm{~V})\end{array}$

Reference intrinsic (X346n) and single p-i-n structure (X343n) $300 \mu \mathrm{s}, 1 \mathrm{~ms}, 3 \mathrm{~ms} \quad 300 \mu \mathrm{s}$ $-0.1$ 0.3

Single p-i-n structure (X329n)

$75 \mu \mathrm{s}, 100 \mathrm{~ms}, 125 \mathrm{~ms} 350 \mu \mathrm{s}$ $-0.1$ 0.25

Tandem solar cell structure (NI78n)

$\begin{array}{cccc}300 \mu \mathrm{s}, 1 \mathrm{~ms}, 3 \mathrm{~ms} & 300 \mu \mathrm{s} & -0.1 & 0.3 \\ 10 \mathrm{~ms} & 300 \mu \mathrm{s} & -0.1,-0.2,-0.3 & 0.3 \\ 2 \mathrm{~ms} & 300 \mu \mathrm{s} & -2 & 0.1 \\ 10 \mathrm{~ms} & 300 \mu \mathrm{s} & -2,-3,-4 & 0.1\end{array}$

The sample included two p-i-n structures of $\mathrm{p}$ GaAs: Zn/i GaAs/n GaAs:Si and p InGaAsN/i InGaAsN/n GaAs with $\mathrm{n}^{++}{ }_{-} \mathrm{p}^{++}$InGaAs-based tunnel junction (TJ) between them. For comparison purposes, in addition three basic structures were also investigated.

Comparison of the measured results included one intrinsic GaAs sample (X346) grown at a temperature of $585^{\circ} \mathrm{C}$, and two p-i-n structures grown at $670{ }^{\circ} \mathrm{C}$, where the basic GaAs p-i-n layer (X343n and X329n) had approximately the same layout as the upper p-i-n structure of the tandem solar cell (Fig. 1). Different experiments were made to optimize the measurement parameters and to obtain evaluable spectra. Also the effect of measurement parameters on the resulting DLTFS signals was tested. Despite the fact that a wide range of measured data were obtained, only the most reliable results are shown. Figure 1 illustrates the structural properties of the investigated semiconductor structures.

\subsection{DLTFS measurements}

The DLTFS method is based on measurements of capacitance differences caused by emission and capture processes from deep energy levels in the semiconductor structure. Charge carriers are unloaded from a specific part of the depletion region by applying a reverse voltage followed by filling voltage excitation and measurement of the capacitance transient signal. The used parameters for signal comparison are summarized in Tab. 1, where the width of the measured capacitance transient signal is $T_{W}$, the reverse voltage applied on the structure is $U_{R}$, the filling voltage is $U_{p}$, and finally the pulse width of the filling voltage is $t_{p}$. Measurements were carried out at different times and reverse voltage variations for the temperature range from $85 \mathrm{~K}$ to $550 \mathrm{~K}$.

First, the intrinsic GaAs sample X346n and the basic p-i-n structures X329n and X343n were tested. In the case of structure X346n three deep energy levels were obtained labelled as ET1, ET2 and HT1 at approximate temperatures 350, 400 and $450 \mathrm{~K}$. Furthermore traps labelled as ET2 and ET3 (Fig. 3) were obtained by DLTFS measurements on sample X343n at temperatures $350 \mathrm{~K}$ and 375 K. Structure X329n exhibited responses from the deep energy level HT1 at temperature of $375 \mathrm{~K}$. The presence of the deep energy level HT1 was confirmed in all three cases. Variation of the capacitance transients period width ensured different signals thereby more data for analysis.

Second, the tandem solar cell NI78n was investigated. Different reverse voltages and period widths were applied on the sample. We notice that only by different reverse voltages we were able to measure entirely different defect types (Fig. 3). This was not achieved by period width variation. As illustrated in Fig. 3, a lower value of the 


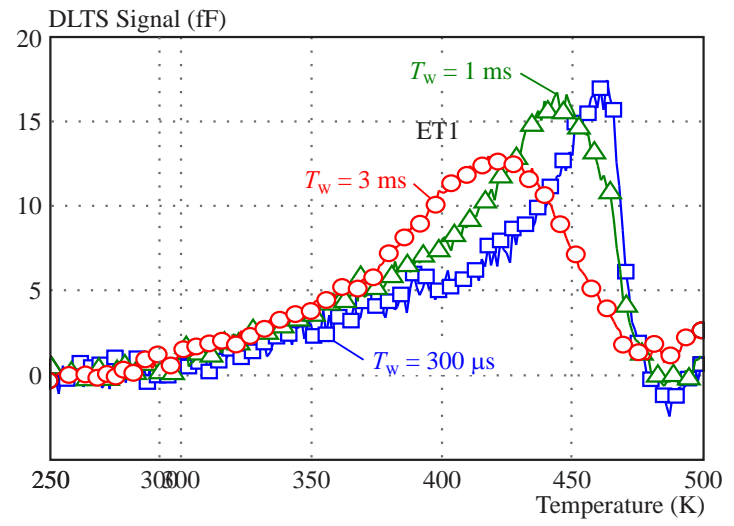

(a)

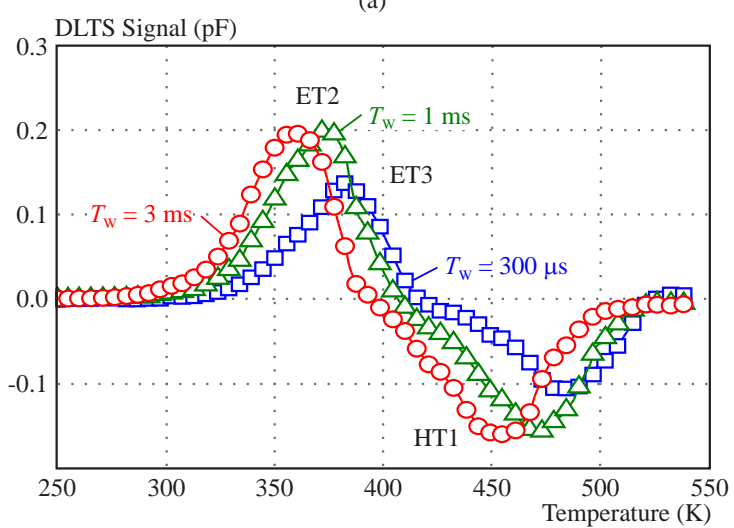

(c)

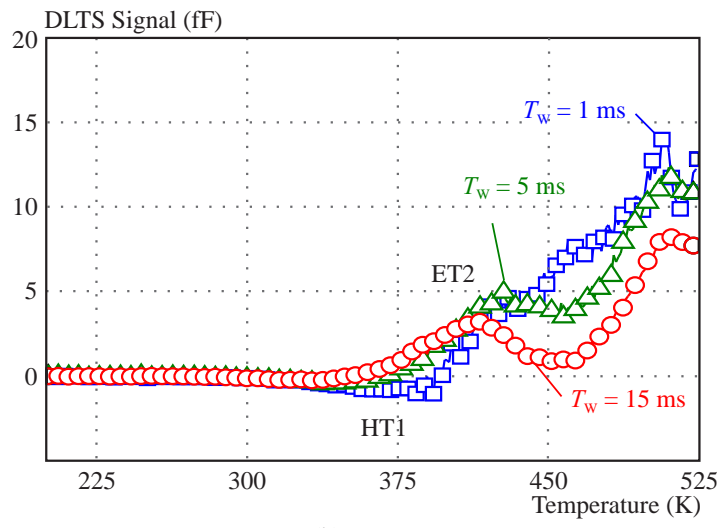

(b)

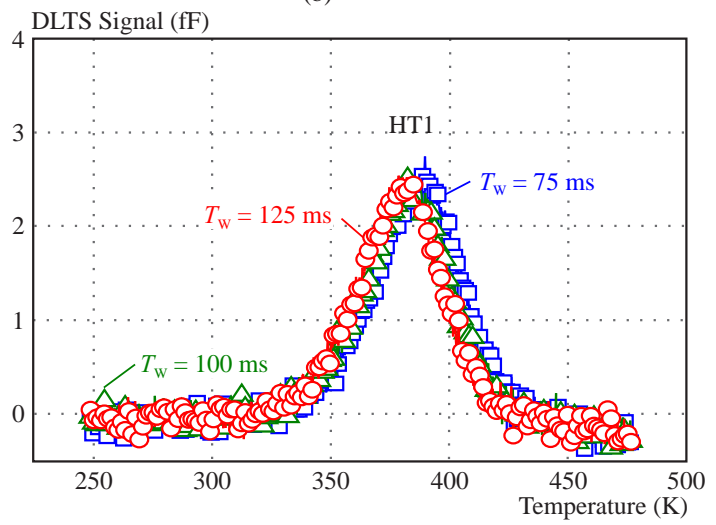

(d)

Fig. 2. Measured DLTFS spectra on samples, comparison at different capacitance transient period widths: $(\mathrm{a})-\mathrm{X} 346 \mathrm{n}, t_{p}=300 \mu \mathrm{s}$, $U_{R}=-0.1 \mathrm{~V}, U_{p}=0.3 \mathrm{~V},(\mathrm{~b})-\mathrm{X} 346 \mathrm{n}, t_{p}=3 \mu \mathrm{s}, U_{R}=-0.5 \mathrm{~V}, U_{p}=0.05 \mathrm{~V},(\mathrm{c})-\mathrm{X} 343 \mathrm{n}, t_{p}=300 \mu \mathrm{s}, U_{R}=-1 \mathrm{~V}, U_{p}=0.25 \mathrm{~V},(\mathrm{~d})$ $-\mathrm{X} 329 \mathrm{n}, t_{p}=350 \mu \mathrm{s}, U_{R}=-1 \mathrm{~V}, U_{p}=0.25 \mathrm{~V}$,

reverse voltage ensured a more significant signal for the deep energy level HT2 appropriate for the mathematical evaluation process.

\subsection{DLTFS evaluation}

The experimental measurements are followed by evaluation processes, thus the analytical part of the DLTFS investigation, hence the calculation of the Arrhenius curve for each deep energy level and determination of the main trap parameters: activation energy, capture cross section and trap concentration $[4,5]$. The key moment of the DLTFS analysis is the usage of proper evaluation methods to be able to calculate these parameters. This investigation was aided by the direct Arrhenius evaluation method consisting in direct calculation of the Arrhenius curve according to the measured capacitance transient signals and the set of evaluation input parameters [6].

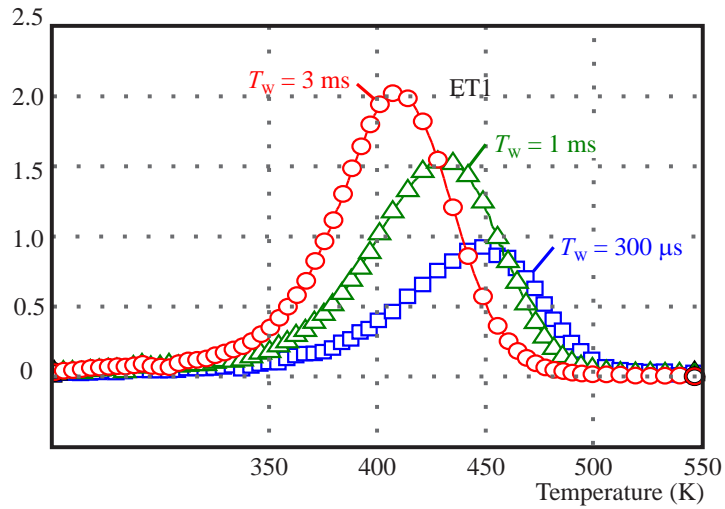

(a)

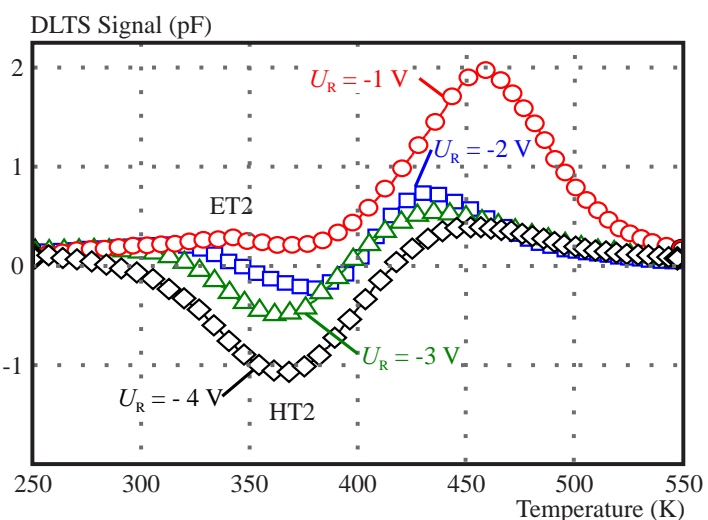

(b)

Fig. 3. Measured DLTFS spectra of the tandem solar cell NI78n, comparison at different (a) - capacitance transient period, $t_{p}=300 \mu \mathrm{s}$, $U_{R}=-0.1 \mathrm{~V}, U_{p}=0.3 \mathrm{~V}$, and $(\mathrm{b})-$ reverse voltage, $T_{w}=10 \mathrm{~ms}, t_{p}=300 \mu \mathrm{s}, U_{p}=0.3 \mathrm{~V}$, 


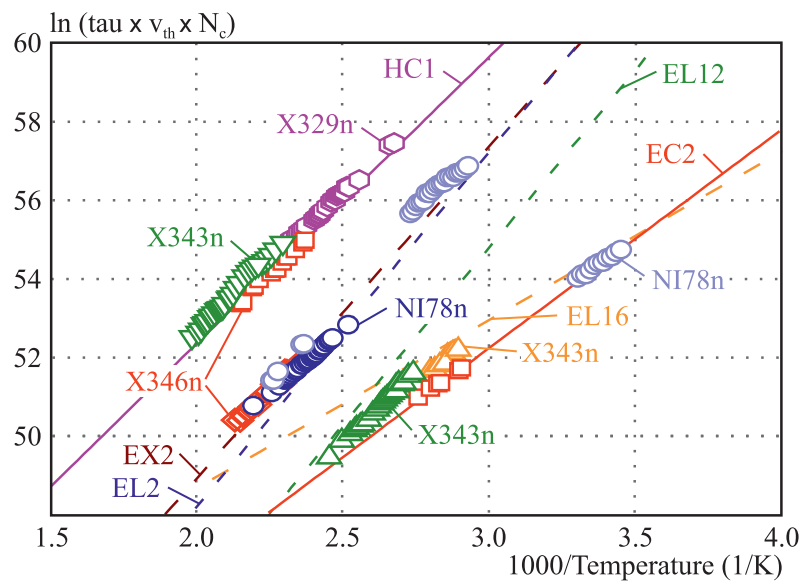

Fig. 4. Calculated Arrhenius curves of the investigated samples, comparison of obtained results of the intrinsic X346n, p-i-n X329n and $\mathrm{X} 343 \mathrm{n}$, and tandem solar cell NI78n structures

Table 2. Calculated deep energy level parameters of the investigated structures

\begin{tabular}{cccccc}
\hline Label & \multirow{2}{*}{ Structure } & $\begin{array}{c}\text { Energy } \\
(\mathrm{eV})\end{array}$ & $\begin{array}{c}\text { Cross section } \\
\left(\mathrm{cm}^{2}\right)\end{array}$ & $\begin{array}{c}\text { Concentration } \\
\left(\mathrm{cm}^{-3}\right)\end{array}$ & Eval. class \\
\hline ET1 & X346n, NI78n & 0.77 & $2.8 \times 10^{-14}$ & $4.4 \times 10^{15}$ & 70 \\
EX2 [7] & & 0.73 & $1.3 \times 10^{-14}$ & - & - \\
EL2 [8] & & 0.83 & $8.0 \times 10^{-14}$ & - & - \\
ET2 & X346n, NI78n, X343n & 0.47 & $2.5 \times 10^{-16}$ & $1.0 \times 10^{15}$ & 45 \\
EC2 [9] & & 0.48 & $3.8 \times 10^{-16}$ & - & - \\
ET3 & X343n & 0.64 & $2.9 \times 10^{-14}$ & $3.4 \times 10^{13}$ & 60 \\
EL12 [8] & & 0.78 & $1.0 \times 10^{-12}$ & - & - \\
EL16 [10] & & 0.37 & $4.0 \times 10^{-18}$ & - & - \\
HT1 & X346n, X329n, X343n & 0.62 & $2.9 \times 10^{-17}$ & $8.2 \times 10^{13}$ & 50 \\
HC1 [9] & & 0.63 & $4.0 \times 10^{-17}$ & - & - \\
HT2 & NI78n & 0.53 & $1.1 \times 10^{-17}$ & $3.3 \times 10^{15}$ & 30 \\
\hline
\end{tabular}

The main evaluation parameter is the minimal class (evaluation class), which defines the range of the used exponentially classified transient signals from low to high ones. The higher this number, the more accurate results we get. The literature [6] defines this parameter to be at least 40 to get acceptable, reliable and evaluable results. The direct method also includes mathematical separation, where the mentioned parameters are also settable. The separation method is an ideal tool for deconvolution of composite capacitance signals if a multiple defect state is assumed. A simulation method of DLTFS spectra was also utilized in order to verify the obtained data, which means a reverse DLTFS curve calculation according to the trap parameters and temperature range. The aim of the evaluation processes was to compare all measured data and to test the correspondence of the Arrhenius curves by the highest evaluation class with the reference trap curves.

Altogether, parameters for five deep energy levels were evaluated and investigated in all studied structures. Also the influence of the growth temperature on the results was examined. As shown below in the Arrhenius figures, no relations between the growth temperature and the presence of these structural defects were achieved.

The traps present in the intrinsic sample X346n, thus ET1, HT1 and ET2, were confirmed also by the other samples grown at higher temperatures. The single p-i-n sample X343n exhibited also another defect state labelled as ET3, whereas in the case of the $\mathrm{p}-\mathrm{i}-\mathrm{n}$ sample X329n only data of the deep energy level HT1 were obtained. The evaluation class of these results varied from 40 to 50 , which represents a lower accuracy. The most accurate results were obtained in the case of the tandem solar cell structure NI78n, where the deep energy level ET1 was investigated at the highest evaluation class, thus 70 . This was most likely observed as a result of three different trap states ET1, ET2 and HT2 activated at different reverse voltages as discussed earlier. The origin of defect states was tested with a mathematical deconvolution method and compared with reference data (Fig. 4, Tab. 2).

\section{RESULTS AND DISCUSSION}

According to the results obtained by the deconvolution method of the measured spectra of sample NI78n we 


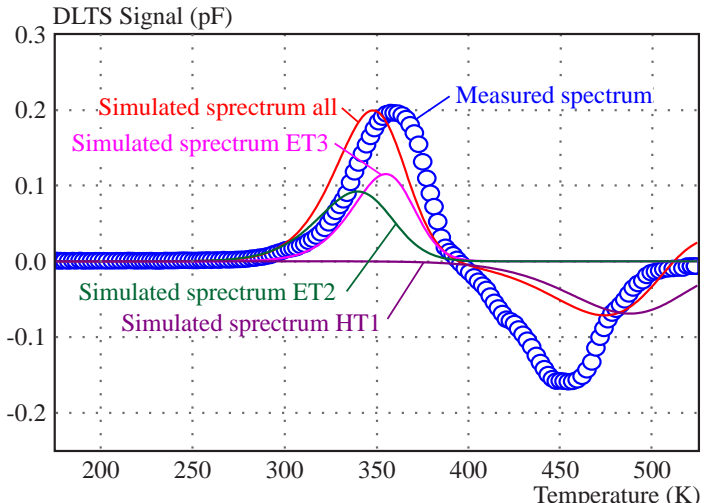

(a)

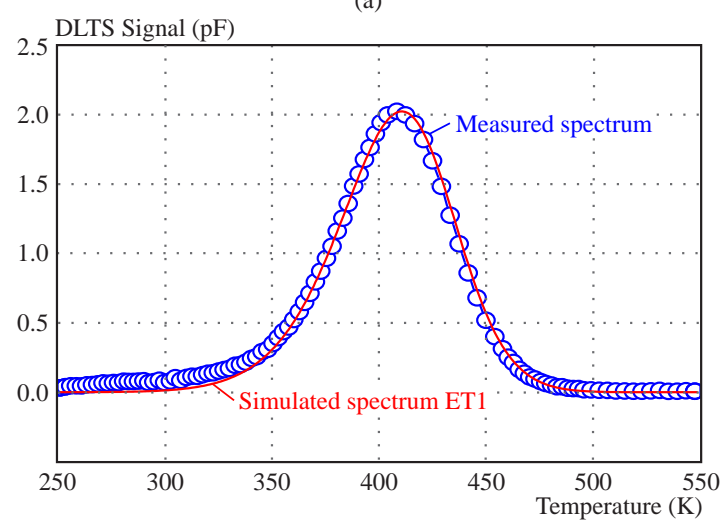

(c)

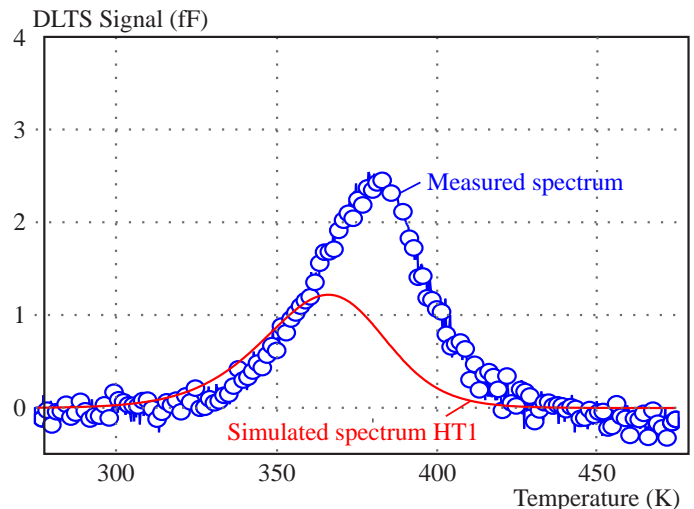

(b)

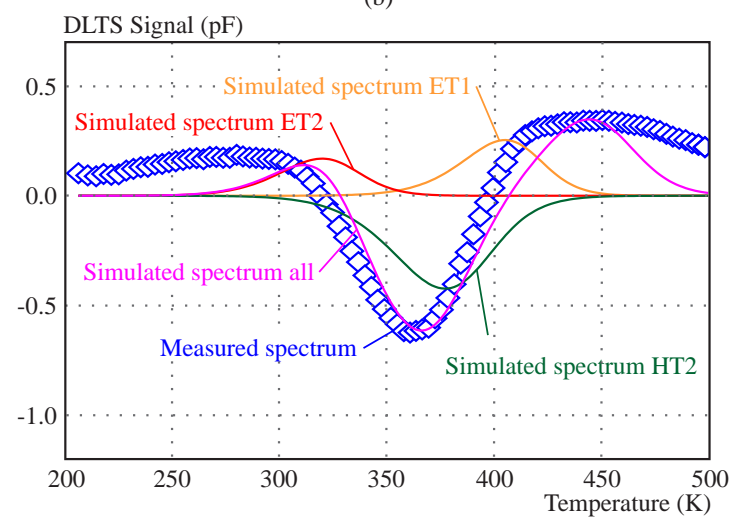

(d)

Fig. 5. Measured and simulated DLTFS spectra of the investigated deep energy levels in samples: (a) - X343n, (b) - X329n, (c) and (d) - NI78n

can determine with high precision the origin of the defect state ET1. After reverse voltage variation and application of the deconvolution method the ET1 in the case of the tandem solar cell, as a complex defect, consisted of responses from deep energy levels corresponding to structural defects in GaAs stated by the literature. These data were confirmed also by DLTFS simulation as shown in Fig. 5, hence ET1, ET2 and HT2 was observed. ET1 with high probability corresponds with native GaAs impurity reported in literature as EX2 [7] with energy of $0.73 \mathrm{eV}$ or EL2 with $0.83 \mathrm{eV}[8]$. The reference trap EC2 [9] with energy of $0.48 \mathrm{eV}$ was stated as a possible origin for ET2.

Correspondences of the calculated energy values with the literature data are acceptably adequate. Unfortunately, the origin of a significant negative peak in the case of lower reverse voltage values could not be determined, the trap level HT2 with calculated energy $0.53 \mathrm{eV}$ of this signal exhibited a low evaluation class 30 . No reference data were stated. This energy level is an object of further studies. Less accurate values were obtained for the deep energy level ET3 which was also a complex defect state probably originated from reference traps EL12 [8], EL16 [10] and EC2 [9]. The calculation accuracy dependence on complex defect state responses was assumed. Deep energy level HT1 was also determined as the reference trap $\mathrm{HC} 1$ [9] with energy $0.63 \mathrm{eV}$. All these data were verified by DLTFS simulation, where acceptable results were achieved. Shifted signals and amplitudes were obtained by parameter determination inaccuracy caused by the presence of complex defect states. Comparison of the achieved deep energy level data is summarized in Tab. 2.

\section{CONCLUSION}

This work deals with the investigation of deep energy levels in semiconductor structures based on compounds produced for tandem solar cell applications. The effects of measurement parameters (reverse voltage and time variation) upon the obtained results were examined. Reverse voltage variation was used as a better approach in the evaluation analytical procedure. Complex defect states were separated and each corresponding parameter was calculated by direct Arrhenius multilevel mathematical deconvolution. The energies of five trap levels $\mathrm{ET} 1=0.77 \mathrm{eV}, \mathrm{ET} 2=0.47 \mathrm{eV}, \mathrm{ET} 3=0.64 \mathrm{eV}$, $\mathrm{HT} 1=0.62 \mathrm{eV}$ and $\mathrm{HT} 2=0.53 \mathrm{eV}$ were identified and compared with reference data.

The obtained Arrhenius curves reasonably agree with reference curves and the differences obtained in the parameter data were with high probability caused by the presence of complex defect states. All obtained deep energy parameters were summarized. Only in the case of the trap level HT2 no reference data were stated due to a low evaluation class 30 . The origin of this deep energy level is the object of further studies. 


\section{Acknowledgement}

This work has been supported by the Scientific Grant Agency of the Ministry of Education of the Slovak Republic (Projects VEGA 1/0377/13, VEGA 1/0439/13 and SOLAR 115721), by a Wrocaw University of Technology statutory grant and by the Slovak-Polish International Cooperation Program no. SK-PL-0005-12.

This paper summarizes in brief the essential issues of a work presented at ADEPT-2014, Advances in Electronics and Photonic Technologies, an international conference held in Tatranska Lomnica, High Tatras, Slovakia, on 1-4 June 2014

\section{REFERENCES}

[1] KAPLAR, R. J.-RINGEL, S. A.-KURTZ, S. R.-KLEM, J. F.-ALlERMAN, A. A.: Applied Physics Letters 80 (2002), 4777.

[2] KAPLAR, R. J.-KWON, D.-RINGEL, S. A.-KURTZ, S. R.-ALlERMAN, A. A.-JONES, E. D.-SIEG, R. M. : Solar Energy Materials \& Solar Cells 69 (2001), 85-91.

[3] FRAAS, L.-PARTAIN, L. : Solar Cells and their Applications, Second edition, John Wiley \& Sons Inc., 2010.

[4] LANG, D. V.: Journal of Applied Physics 45 (1974), 3023.

[5] MILLER, G. L.-LANG, D. V.-KIMBERLING, L. C. : Annual Review of Materials Science 7 (1977), 377-448.

[6] SIEGHARD, W. : Semiconductor Investigations with the DLTFS Method, PhD Thesis, Department of Physics, University of Kassel, 1991.

[7] HARDALOV, CH.-YANCHEV, I.-GERMANOVA, K.-IVANOV, TZV.-SAMURKOVA, L.-KIROV, K.-NIGOHOSIAN, A. : Journal of Applied Physics 71 (1992), 2270

[8] MASSE, G.-LACROIX, J. M.-LAWRENCE, M. F.: Journal of Applied Physics 65 (1989), 1126.

[9] PARTIN, D. L.-CHEN, J. W.-MILNES, A. G.-VASSAMILLET, L. F. : Journal of Applied Physics 50 (1979), 6845.

[10] SCHULTZ, M. : Landolt-Bornstein, New Series III/22b (1989), 207.

Received 15 June 2014

Arpád Kósa (Ing) born in 1987 is a $\mathrm{PhD}$ student at the Institute of Electronics and Photonics, Slovak University of Technology. He received his Ing degree in microelectronics from the Slovak University of Technology in 2013. His research interests include semiconductor defect analysis and investigation by experimental and mathematical methods, electronics and microelectronics, and mathematical evaluation algorithm programming.

Lubica Stuchlíková (Assoc Prof, Dr) graduated from the Faculty of Electrical Engineering, Slovak University of Technology in Bratislava (STU) in 1990, received the $\mathrm{PhD}$ degree in 1996 and was appointed associate professor in 2006. She works as a teacher at the Institute of Electronics and Photonics. Since 1990 she has been interested in semiconductor defects engineering and electrical characterization of semiconductor structures, devices and materials.

Juraj Jakuš (Ing) was born 1989 in Trenčín, Slovakia. He is a doctoral student His research interests include parallel computing, general purpose GPU programming and algorithm tuning. Since 2013 the area of his interest has been diagnostics of diluted nitrides.

Wojciech Dawidowski (MSc, Eng) was born in Tomaszów Lubelski, Poland in 1987. He graduated from Wrocław
University of Technology, Faculty of Microsystem Electronics and Photonics in 2011. He is a PhD student and his research is focused on epitaxial growth of $\mathrm{A}^{\mathrm{III}} \mathrm{B}^{\mathrm{V}}-\mathrm{N}$ semiconductor compounds for solar cells, their fabrication and characterization.

Beata Ściana (Ing, PhD) was born in Wrocław, Poland, in 1965. She graduated in Electronics from the Wroclaw University of Technology, Faculty of Electronics, in 1990. From 1990 to 1993 she worked at the Elwro Electronics Factory in Wrocław. Since 1993 she has worked at Wrocław University of Technology and pursued researches in epitaxial growth (MOVPE method) and material characterization of $\mathrm{A}^{\mathrm{III}} \mathrm{B}^{\mathrm{V}}$ semiconductor compounds for application in advanced microelectronic and optoelectronic devices. She received her $\mathrm{PhD}$ degree in Electronics from Wrocaw University of Technology in 2000 .

Damian Radziewicz (PhD) was born in 1969, Poland. He graduated from Wrocław University of Technology, Faculty of Microsystem Electronics and Photonics, Wrocaw, in 1994. He received his $\mathrm{PhD}$ degree from WUT Wrocław in 2001. Since 2005 he has been engaged as assistant professor at WUT Wrocław. Since 1994 he has been engaged in the research of optoelectronic devices, especially in epitaxy (MOVPE) of $\mathrm{A}^{\mathrm{III}} \mathrm{B}^{\mathrm{V}}$ semiconductor devices and characterization of heterostructures.

Damian Pucicki was born in Šwidnica, Poland, in 1979. He received the MSc degree in materials science from the Faculty of Fundamental Problems of Technology, Wrocław University of Technology (WUT), Wrocław, Poland, in 2002, and the $\mathrm{PhD}$ degree from the Faculty of Microsystem Electronics and Photonics, WUT, in 2006. His interests include the development of technology and structural characterization of diluted nitrides containing structures and quantum dots as well. He had several short-term stays and a one-year long Postdoctoral Fellowship at the University of Wrzburg.

Ladislav Harmatha (Assoc Prof, Ing, PhD) was born in Dobšiná, Slovakia, in 1948. He graduated from the Faculty of Electrical Engineering, STU Bratislava, in 1971, received the $\mathrm{PhD}$ degree in 1984 and was appointed associate professor in 1996. Since 1988 he has worked as a senior scientist in the field of semiconductor defects engineering. His research is focused on defects in semiconductor structures and their characterization by electrical methods (capacitance transient spectroscopy).

Jaroslav Kováč (Prof, Ing, PhD) was born in Tornal'a, Slovakia, in 1947. He graduated from the Slovak University of Technology, Faculty of Electrical Engineering and Information Technology in 1970. Since 1971 he has been engaged in the research of optoelectronic devices technology at the Microelectronics Department of FEI STU. He received a PhD degree (1983) and professor degree (2001) from STU Bratislava. Since 1991 he has been the team leader of the Optoelectronic Group at the Institute of Electronics and Photonics.

Marek Tłaczala (Prof Ing PhD) graduated in electronics from the Faculty of Electronics, Wrocław University of Technology in 1972. In 1973-1976 he worked at the Electrotechnical University in Leningrad (now Sankt Petersburg). He received his $\mathrm{PhD}$ degree in electronic engineering from the Electrotechnical University in Leningrad in 1976 and DSc degree from the Faculty of Microsystem Electronics and Photonics, Wrocaw University of Technology in 2002. Since 2009 he is full professor and head of the Semiconductor Devices Lab in the Faculty of Microsystem Electronics and Photonics, Wroclaw University of Technology. 